\title{
The effect of visceral reception activation (water load test) on autonomic activity and gastric myoelectric activity in gastrointestinal malignancies
}

\author{
Zygulska $\mathrm{AL}^{1}$, Furgala $\mathrm{A}^{2}$, Krzemieniecki $\mathrm{K}^{1,3}$, Gil K² \\ Department of Oncology, Krakow University Hospital, Krakow, Poland. zygulska@poczta.onet.pl
}

\begin{abstract}
OBJECTIVES: The aim of this study was to analyze the effect of water load test (WLT) on heart rate variability (HRV), blood pressure variability (BPV), hemodynamic parameters and gastric myoelectric activity in gastrointestinal $(\mathrm{Gl})$ cancer patients.

BACKGROUND: WLT activates gastrointestinal mechanoreception and osmoreception, and hence, can indirectly modulate autonomic activity. METHODS: Eighty patients (mean age 61.2 years) were enrolled, along with the group of healthy controls. HRV, BPV and electrogastrography (EGG) were recorded at rest (in a fasted state) and after water uptake at $100 \mathrm{ml} / \mathrm{min}$.

RESULTS: WLT contributed to an increase in the percentages of normogastria time, from $37.3 \%$ to $50.0 \%$ $(p=0.02)$ and from $42.3 \%$ to $47.7 \%(p=0.01)$, respectively in colon and rectal cancer. Cancer patients presented lower values of HRV indices determined on linear analysis at rest and after WLT.

CONCLUSIONS: A slight predominance of the sympathetic component was observed in response to WLT, which was reflected by changes in hemodynamic parameters. The response to WLT is a consequence of GI mechanoreception and osmoreception activation and resultant pressure reaction. This effect was disrupted by the neoplastic process within the GI tract, especially in gastric and colon malignancies, but not in rectal cancer (Tab. 2, Fig. 3, Ref. 40). Text in PDF www.elis.sk

KEY WORDS: autonomic nervous system, gastric myoelectric activity, water uptake, heart rate variability, blood pressure variability, gastrointestinal cancer.
\end{abstract}

\section{Introduction}

Water load or drink test (WLT) is a non-invasive method for the assessment of gastric distension. The test is easy to conduct and well-tolerated. Preliminary studies confirmed the reproducibility of WLT results in healthy adults (1). WLT causes gastric distension and evokes gastric motility response but without a complex hormonal response typical for a caloric test meal. The evidence from preliminary experiments suggests that the results of the drink test correlated well with the outcomes of barostat

\footnotetext{
${ }^{1}$ Department of Oncology, Krakow University Hospital, Krakow, Poland, ${ }^{2}$ Department of Pathophysiology, Jagiellonian University Medical College, Krakow, Poland, and ${ }^{3}$ Department of Oncology, Jagiellonian University Medical College, Krakow, Poland

Address for correspondence: A.L. Zygulska, MD, PhD, Department of Oncology, Krakow University Hospital, 2 Jakubowskiego St., 30-688 Krakow, Poland.

Phone: +48.694 .502880$

Acknowledgement: This study was supported from the specific subsidy of the Ministry of Science and Higher Education in Poland for holding research capacity (grant No. K/ZDS/004569). The funding body had no role in this study or its publication.
}

studies (2). Patients with functional diseases (FD) were shown to present with impaired drinking capacity, but the latter can also be observed in a substantial proportion of healthy persons $(3,4)$. WLT can be used to detect FD with intact gastric function but abnormal visceral perception $(5,6)$. The test measures the response of the autonomic nervous system (ANS), which is caused primarily by the activation of gastric mechanoreceptors (1).

Previous studies demonstrated that administration of $500 \mathrm{ml}$ of water causes an increase in blood pressure (BP) in patients with hypotension, which is associated with sympathetic activation (8). WLT was shown to induce a $10 \mathrm{mmHg}$ increase in blood pressure in the middle- and old-aged healthy subjects. Rapid intake of cold water is known to be effective in the treatment of orthostatic intolerance and postprandial hypotension. A normal response to this stimulus is a $16 \mathrm{mmHg}$ increase in blood pressure, resulting from stimulation of the sympathetic nervous system $(9,10)$.

Electrogastrography (EGG) is widely used to evaluate the myoelectrical activity of the stomach. While EGG cannot be used to diagnose a specific disease, it provides information about upper gastrointestinal tract motility in many pathological conditions, such as gastroparesis in diabetic neuropathy, gastroesophageal reflux disease, cyclic vomiting in children and functional dyspepsia $(11,12)$. Abnormal results of EGG correlated with the severity of 
symptoms in patients with unresectable gastric cancer (13). Our previous studies showed that colorectal and gastric cancers affect gastric myoelectric activity, decreasing normogastria and slow wave coupling. Moreover, GI cancer patients did not show adequate gastric motility response to food. These disturbances correlated with cancer-induced autonomic disturbances (14).

EGG was validated as a reliable and reproducible method to measure response to WLT (3). WLT induced gastric distention using a natural distention stimuli such as water and assessed gastrointestinal symptoms in patients i. e. with functional disorders. The volume of ingested water indicated feeling of fullness in examined subjects $(2,3)$. Gastric distention sent signals from the stomach to the brain via vagal nerve stimulation what led to the perception of satiety feeling (15). It is worth mentioning, that meal volume and its composition influence gastric myoelectrical activity (16).

The time and spectral analysis of heart rate variability (HRV) and analysis of blood pressure variability (BPV) are used for a noninvasive assessment of autonomic activity. HRV reflects variation in the time intervals between heartbeats, and BPV is a measure of variation between systolic or diastolic blood pressure. HRV is determined with non-linear methods to analyze temporal similarities in the signals. Previous studies demonstrated that changes in HRV spectra might be associated with ischemic heart disease, heart failure, diabetes mellitus, the risk of sudden cardiac death, irritable bowel syndrome and functional dyspepsia $(17,18,19)$. The frequency domain analysis of HRV and BPV estimated the vagal nervous activity. The simultaneous recording ECG (electrocardiogram), BP and EGG is necessary for complex evaluation of neurological (vagal activity, brain-gut axis) regulation GI. Likewise autonomic dysfunction in cancer patients, especially disruption of the sympathovagal balance, may impair regulation of the cardiovascular system $(20,21,22)$.

Published data regarding autonomic function and gastric myoelectric activity in gastrointestinal malignancies are sparse and inconclusive $(14,23,24,25)$. Furthermore, little is known about the mechanisms of gastrointestinal mechanoreception and osmoreception activation during the course of neoplastic processes. Therefore, the aim of this study was to investigate the effect of water intake (visceral receptor activation) on ANS activity (measured as HRV, BPV) and gastric motility (measured by EGG) in patients with gastrointestinal malignancies compared with healthy individuals.

\section{Patients and methods}

The study included 80 patients ( 37 men and 43 women, mean age $61.2 \pm 7.8$ years) diagnosed with gastrointestinal malignancies: gastric cancer (group A, $\mathrm{n}=20,15$ men and 5 women, mean age $62.9 \pm 10.7$ years), colon cancer (group $\mathrm{B}, \mathrm{n}=30,8$ men and 22 women, mean age $64.8 \pm 10.2$ years) and rectal cancer (group $\mathrm{C}, \mathrm{n}=$ 30,14 men and 16 women, mean age $61.2 \pm 9.7$ years). All patients were recruited at the Department of Oncology, University Hospital in Krakow (Poland) between September 2014 and August 2016. Control group comprised of 30 healthy asymptomatic subjects (14 men and 16 women, mean age $58.4 \pm 11.6$ years). All experiments were conducted at the Department of Oncology and Department of Pathophysiology, Jagiellonian University Medical College in Krakow (Poland). The protocol of the study was approved by the Local Bioethics Committee (decision no. KBET/98/B/2014). All procedures involving human participants were conducted in accordance with the 1964 Helsinki Declaration and its later amendments or comparable ethical standards.

None of the study participants showed abnormalities in complete blood count parameters and results of biochemical tests for kidney and liver function. The vast majority of the cancer patients (75\%) underwent a radical surgical treatment. The group of 80 cancer patients included 28 (35\%) persons who received radiotherapy. Systemic treatment (chemotherapy and targeted therapy with trastuzumab) was given in 54 patients $(67.5 \%)$

The inclusion criteria of the study were 1) histological evidence of gastric or colorectal carcinoma, 2) lack of neoplastic cachexia, 3) at least 18 years of age, 4) discontinuation of all medications with potential effect on gastric motility three days prior to EGG, 5) Eastern Cooperative Oncology Group (ECOG) performance status of 1 or 0 , and 6) written informed consent to participate in the study.

The subjects were excluded from the study if they presented with cardiovascular diseases, neurological disorders, gastrointestinal disorders other than carcinoma, diabetes mellitus, obesity (body mass index $>30 \mathrm{~kg} / \mathrm{m}^{2}$ ) or cachexia, smoked cigarettes, abused alcohol, took medications with an established effect on gastric myoelectric parameters, had a history of abdominal surgery other than anticancer treatment, were pregnant or suffered from chronic disorders that might affect gastrointestinal and/or autonomic function.

The measurements were taken between 8.00 a.m. and 10.00 a.m., after 12 hours fast. The examination was carried out with the participants in a supine position, at a quiet laboratory, in a relaxed atmosphere and neutral ambient temperature $\left(23 \pm 1{ }^{\circ} \mathrm{C}\right)$.

The study subjects were asked not to undertake any activities that might evoke changes in the ANS and not to take any medications with a known effect on autonomic function and gastrointestinal (GI) motility. ECG signal, continuous beat-to-beat blood pressure and cardiovascular hemodynamic recordings were obtained by means of plethysmography, cardiac impedance signal with Task Force Monitor 3040 (CNSystems, Austria), and gastric myoelectric activity (EGG) with electrogastrography Polygraf NET (Medtronic, USA) as described previously by Simonian et al, Wang et al and Krusiec-Świdergol et al $(26,27,28)$. The examination began after a 20 -min rest, after the subject achieved a respiratory rate of 14 breaths $/ \mathrm{min}$. The measurements were taken at rest (in a fasted state), during WLT ( $5 \mathrm{~min}$ ) and after water ingestion (60 $\mathrm{min})$.

\section{$E G G$}

Gastric myoelectric activity was recorded with standard four cutaneous active electrodes. The abdominal skin at the recording sites was shaved and abrasioned with Every paste before applying six $\mathrm{Ag} / \mathrm{AgCl}$ electrodes to reduce impedance. The hair, if present, was shaved. The electrodes were placed on the abdomen 
according to recommendation from study Krusiec-Świdergol and Kasicka-Jonderko et al $(28,29)$. The electrodes were connected to Medtronic POLYGRAM NET EGG 311224 system (Medtronic Functional Diagnostics A/S). The four active electrodes were localized: the third active (3) electrode was fixed in the midline, halfway between the xiphoid process and the umbilicus (which is a standard position for a single-channel electrogastrography), the fourth (4) electrode was attached at the same level as the third electrode, but 4-6 cm to the right, whereas the second (2) and the first (1) electrodes were placed at $4-6 \mathrm{~cm}$ intervals on a line connecting the third electrode with the left costal margin. The reference electrode (Ref) was fixed at the interception of a horizontal line passing through the location of the first electrode and a vertical line starting at the location of the third electrode. The grounding electrode (Gnd) was placed on the left costal margin, on a horizontal line beginning at the location of the third electrode. Finally, a motion sensor was taped to the abdominal skin.

EGG parameters were obtained from the first and second channel in gastric cancer patients after subtotal gastrectomy, and from the third channel - in colorectal cancer patients $(28,29)$.

We used multichannel EGG system Polygraf with a low pass filter of $15 \mathrm{cpm}$ and with high pass filter of $1.8 \mathrm{cmp}$. The primary signal was sampled at $105 \mathrm{~Hz}$. Raw signals acquired every $256 \mathrm{~s}$ are filtered and processed by a fast Fourier transformation using a Hamming window to obtain EGG parameters. The following: percentage of dysrrhythmia time (0.5-2 cpm - bradygastria; 4.0-10.0 $\mathrm{cpm}$ - tachygastria and arrhythmia), percentage of normogastria (2-4 cpm), dominant frequency (DF); dominant power of dominant frequency (DP).

The percentage of slow wave coupling (SWC) defined as the relative time within a given period during which the difference in dominant frequency between two channels was $<0.2 \mathrm{cpm}$, and the average percentage of slow wave coupling (ACSWC) obtained by averaging the results from six identified channel pairs. Changes in the EGG dominant power depending on the fed state and the fasten situation appear to reflect gastric contractility (19).

\section{ANS}

Autonomic activity was estimated based on linear (time and frequency) analysis of HRV and frequency analysis of BPV. The frequency domain analysis of HRV and BPV provided information about a balance between sympathetic and parasympathetic tone (30). The frequency domain analysis of RR intervals (ECG recordings obtained from six conventional leads) and arterial blood pressure (continuous beat-to-beat blood pressure recording) was carried out by Aggregating Algorithm Regression (AAR), using Task Force software V Monitor 2.2. The time domain and nonlinear HRV parameters were calculated with Kubios Premium 3.1 software (Kuopio, Finland).

The following frequency domain analysis HRV parameters were evaluated: LF (component of the low-frequency range, $0.04-0.15 \mathrm{~Hz}$, modulated by both the sympathetic and parasympathetic nervous system and associated with baroreceptor activity), HF (component of the high-frequency range, 0.15-0.4 Hz, modulated by the parasympathetic nervous system, associated with respiration and blood pressure changes), $\mathrm{LF} / \mathrm{HF}$ ratio, reflecting interactions of both types of autonomic modulation and normalized components, LFnu [LF/(TP-VLF)*100] and HFnu [HF/(TPVLF)*100] (29, 31).

The succeeding frequency domain BPV indices such as PSD, VLF, HF similar like in HRV analysis and mid frequency $(0.1 \mathrm{~Hz})$ oscillations (MF), i.e. the so-called Mayer waves, and low frequency $(<0.1 \mathrm{~Hz})$ oscillations $(\mathrm{LF})$ - depending on many physiological phenomena were calculated. MF and LF were analyzed together as the low frequency spectrum controlled by vascular innervation and modulated by autonomic activity.

\section{Cardiovascular hemodynamic indices}

The following hemodynamic parameters were analyzed: HR - heart rate, $\mathrm{sBP}$ - systolic blood pressure, $\mathrm{dBP}$ - diastolic blood pressure, $\mathrm{mBP}$ - mean blood pressure (beat-to-beat).

Baroreceptor reflex sensitivity (BRS) - a spontaneous activity of baroreceptors determined using the "sequence method" to detect rising sequences, i.e. an increase in systolic blood pressure and longer R-R intervals, and falling sequences, i.e. a decrease in systolic blood pressure and shorter R-R intervals, in continuous beat-to-beat time series of R-R intervals and systolic blood pressure recordings, and baroreceptor effectiveness index (BEI)baroreceptor sequences/events ratio for lags $0 \mathrm{n} 1$ and 2, as related to the number of BP ramps.

\section{Water load test (WLT)}

After a 30-minute simultaneous recording of EGG, ECG and BP, the study subjects were asked to drink no caloric water at a slow rate of $100 \mathrm{ml} / \mathrm{min}$; as the recordings were obtained for 5 minutes, the total volume of water ingested during the WLT was $500 \mathrm{ml}$. The volume of water after ingestion of which the patient reported the feeling of stomach fullness was recorded.

\section{Statistical analysis}

TIBCO Statistica for Windows, version 13.3 PL (TIBCO Software Inc., Palo Alto, CA USA, Jagiellonian University license) was used for database management and statistical analysis. Normal distribution of quantitative variables was verified with the ShapiroWilk test, and their statistical characteristics were presented as means and standard deviations (SD). Variables that did not satisfy the criteria of normality were presented as medians (Me), minimum and maximum values (min-max). DP values from EGG were subjected to log-normal transformation prior to further analyses. The significance of intergroup differences was verified with oneway ANOVA with Tuckey post-hoc test for normally distributed variables, or with one-way ANOVA on ranks (Kruskal-Wallis test) for variables without the normal distribution. The significance of patients and control group differences was verified with Student t-test for dependent variables. Wilcoxon singed rank test was used to compare normally and non-normally distributed variables.

The power of associations between EGG parameters, HRV indices, hemodynamic and therapy type (radical vs palliative), age, sex, type of GI cancer, systemic therapy and/ or radiotherapy performed was estimated on the basis of Spearman's coefficients of 
Tab. 1. Electrogastrographic parameters in GI cancer patients, determined before and after the ingestion of $500 \mathrm{ml}$ of water (WLT).

\begin{tabular}{|c|c|c|c|c|c|c|}
\hline & EGG & $\begin{array}{c}\text { Group A } \\
\text { [Me] }\end{array}$ & $\begin{array}{c}\text { Group B } \\
{[\mathrm{Me}]}\end{array}$ & $\begin{array}{c}\text { Group C } \\
{[\mathrm{Me}]}\end{array}$ & $\begin{array}{c}\text { Control } \\
{[\mathrm{Me}]}\end{array}$ & $\mathrm{p}^{*}$ \\
\hline \multirow{7}{*}{ 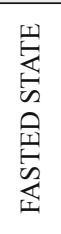 } & $\mathrm{DF}[\mathrm{cpm} / \mathrm{min}]$ & 2.6 & 2.8 & 2.8 & 3.1 & $0.03^{1,3} / 0.07^{4,5,6}$ \\
\hline & $\mathrm{DP}\left[\mu \mathrm{V}^{2}\right]$ & 12.9 & 11.4 & 12.1 & 10.6 & $0.035^{1,2,3} / 0.02^{4,6}$ \\
\hline & Normogastria [\%] & 46.4 & 38.6 & 41.9 & 79.1 & $0.009^{1,2,3} / 0.002^{4}$ \\
\hline & Bradygastria [\%] & 8.3 & 8.2 & 8.9 & 2.1 & $0.0000^{1,2,3}$ \\
\hline & Tachygastria [\%] & 8.3 & 7.6 & 8.0 & 1.8 & $0.001^{1,2,3} / 0.007^{4,6}$ \\
\hline & Arrhythmias [\%] & 36.4 & 38.5 & 32.6 & 6.8 & $0.035^{1,2,3}$ \\
\hline & ACSWC [\%] & 45.2 & 47.1 & 50.8 & 72.6 & $0.0000^{1,2,3}$ \\
\hline \multirow{7}{*}{ 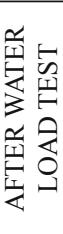 } & $\mathrm{DF}[\mathrm{cpm} / \mathrm{min}]$ & 2.7 & 2.8 & 2.9 & 2.8 & $0.03^{1,2} / 0.03^{5}$ \\
\hline & $\mathrm{DP}\left[\mu \mathrm{V}^{2}\right]$ & 12.7 & 11.6 & 12.4 & 11.2 & $0.035^{1,2,3} / 0.02^{4,6}$ \\
\hline & Normogastria [\%] & 44.5 & 50.0 & 47.7 & 66.7 & $0.0000^{1,2,3}$ \\
\hline & Bradygastria [\%] & 10.6 & 7.4 & 8.2 & 5.1 & $0.001^{1,2,3} / 0.0001^{4,5}$ \\
\hline & Tachygastria [\%] & 7.4 & 7.4 & 7.9 & 5.9 & $0.009^{1 / 0.002^{2}}$ \\
\hline & Arrhythmias [\%] & 38.1 & 33.3 & 32.7 & 16.7 & $0.001^{1,2,3} / 0.002^{4,5}$ \\
\hline & ACSWC [\%] & 45.85 & 48.1 & 51.5 & 78.3 & $0.001^{1,2,3}$ \\
\hline
\end{tabular}

$\mathrm{Me}$ - median value; 1 - $2 \mathrm{cpm}$ - bradygastria, 2 - $4 \mathrm{cpm}$ - normogastria, 4 - $10 \mathrm{cpm}$ - tachygastria, DF - dominant frequency, DP - dominant power, ACSWC - average percentage of slow-wave coupling.

$\mathrm{p}<0.05$; (ANOVA analysis): $\mathrm{p}^{1}$ - differences group A vs the controls; $\mathrm{p}^{2}$ - differences group B vs the controls; $\mathrm{p}^{3}$ - differences group $\mathrm{C}$ vs the controls; $\mathrm{p}^{4}$ - differences group A vs group $\mathrm{B} ; \mathrm{p}^{5}-$ differences group A vs group $\mathrm{C} ; \mathrm{p}^{6}-$ differences group $\mathrm{B}$ vs group $\mathrm{C}$ rank correlation. The results of all tests were considered significant at $\mathrm{p}<0.05$.

\section{Results}

\section{EGG parameters}

In the control group, WLT contributed to an increase in average percentage slow wave coupling (ACSWC) from $72.6 \%$ to $78.3 \%(\mathrm{p}=0.04)$ and in the percentage of arrhythmia from $6.8 \%$ to $16.7 \%$ (p = $0.001)$, but a decrease in dominant slow wave frequency (DF) from 3.1 to $2.8 \mathrm{cpm}(\mathrm{p}$ $=0.03$ ) and the percentage of normogastria $79.1 \%$ to $66.7 \%(p=0.03)$. WLT did not exert a significant effect on the percentage of bradygastria and tachygastria (Fig. 1).

During examination in a fasted state, patients from groups A, B and C presented
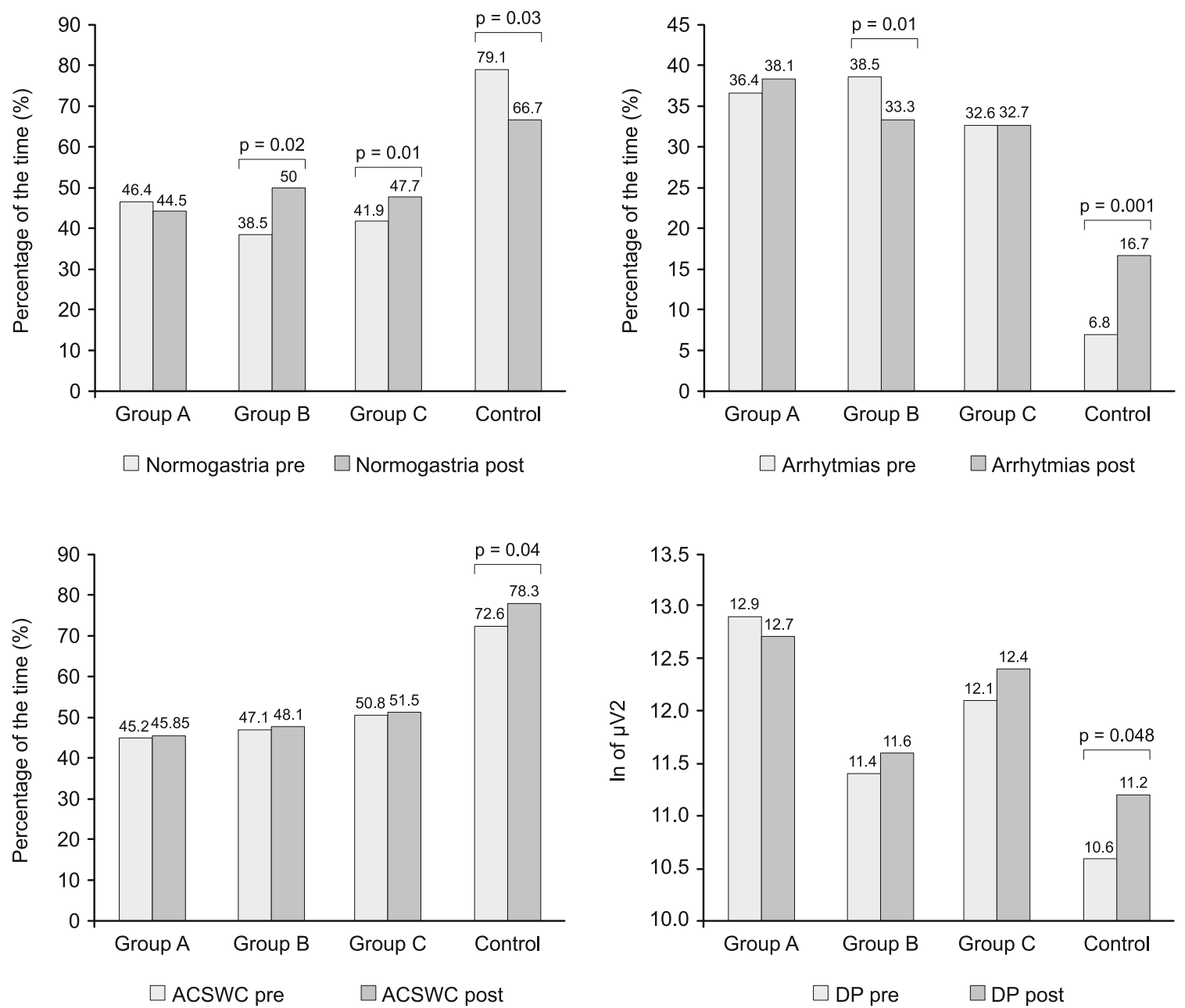

Fig. 1. Changes in EGG parameters in response to WLT in the study groups. $p<0.05$ - the Wilcoxon singed rank test, pre - before WLT, post - after WLT. 

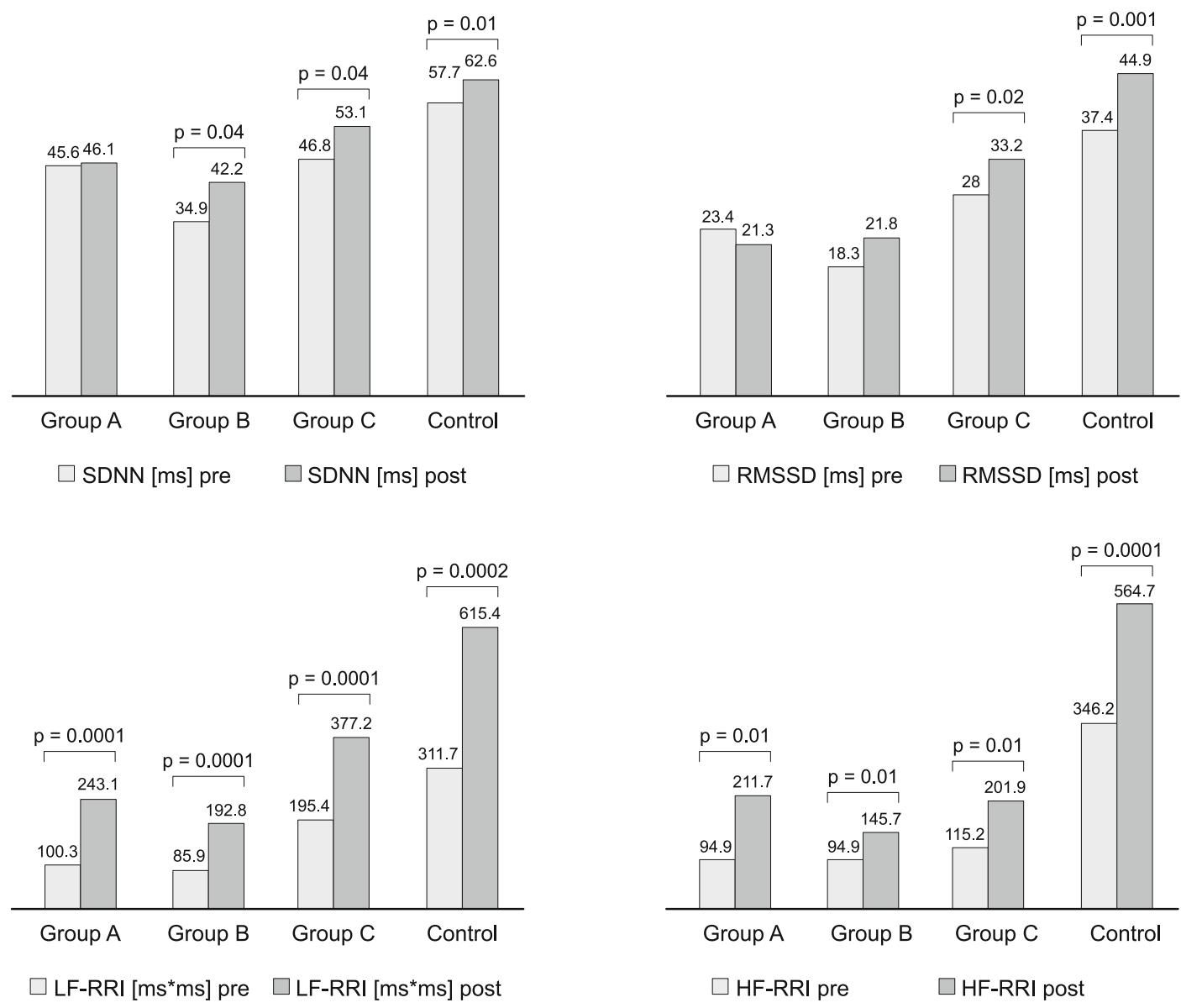

Fig. 2. Selected time and spectral domain HRV indices in the study groups, determined before and after WLT. $p<0.05-$ the Wilcoxon singed rank test, pre - before WLT, post - after WLT.

with significantly lower percentages of normogastria time, lower average percentage slow wave coupling (ACSWC) and higher values of slow wave dominant power than the controls (Tab. 1).

After the WLT, a decrease in the percentage of normogastria time was observed in group A, from $46.4 \%$ to $44.5 \%(\mathrm{p}>0.05)$, along with an increase in bradygastria time from $8.3 \%$ to $10.6 \%$. In groups $\mathrm{B}$ and $\mathrm{C}$, an increase in the percentage of normogastria time was observed, from $38.6 \%$ to $50.0 \%(\mathrm{p}=0.02)$ and from $41.9 \%$ to $47.7 \%$, respectively and from $41.9 \%$ to $47.7 \%(p=0.01)$, respectively along with a non-significant increase in ACSWC ( $p>$ 0.05 ). However, the values of parameters in both cancers did not reach the levels observed in the controls, i.e. $78.3 \%$ and $66.7 \%$, respectively. The results are summarized in Table 1 and Figure 1.

\section{$H R V$}

Control group

Stomach distension evoked by the WLT contributed to an increase in HRV indices: LF (from 311.7 to $615.4 \mathrm{~ms}^{2}, \mathrm{p}=0.0002$ ) and HF (from 346.2 to $564.7 \mathrm{~ms}^{2}, \mathrm{p}=0.0001$ ). The results are presented in Table 2 and Figure 2.
Group A (gastric cancer)

The values of two HRV parameters determined at rest, LF and $\mathrm{HF}$, turned out to be significantly lower in gastric cancer patients than in the controls (LF: 113.4 vs $311.7 \mathrm{~ms}^{2}, \mathrm{p}=0.002$; HF: 92.1 vs $\left.342.6 \mathrm{~ms}^{2}, \mathrm{p}=0.001\right)$. However, WLT contributed to a substantial increase in both LF and HF values in gastric cancer group, by $106 \%(\mathrm{p}=0.0001)$ and $129 \%(\mathrm{p}=0.01)$, respectively (Fig. 2).

\section{Group B (colon cancer)}

The resting values of HRV parameters, LF and HF, turned out to be significantly lower in colon cancer patients than in the controls (LF: 88.7 vs $311.7 \mathrm{~ms}^{2}$, p = 0.002; HF: 91.8 vs $346.2 \mathrm{~ms}^{2}$, p $=0.001)$. WLT contributed to a $117 \%(\mathrm{p}=0.0001)$ and $58 \%(\mathrm{p}$ $=0.01$ ) increase in LF and HF values, respectively but these HRV parameters did not reach the levels observed in the controls $(\mathrm{p}=$ 0.02) (Fig. 2). The values of all HRV indices are shown in Table 2.

\section{Group C (rectal cancer)}

In rectal cancer patients, the values of HRV parameters determined at rest were significantly lower than in the controls 
Tab. 2. Hemodynamic parameters in patients with various gastrointestinal malignancies and healthy controls, determined in a fasted state and after WLT.

\begin{tabular}{|c|c|c|c|c|c|c|}
\hline & parameters & $\begin{array}{c}\text { Group A } \\
\text { [Me] }\end{array}$ & $\begin{array}{c}\text { Group B } \\
{[\mathrm{Me}]}\end{array}$ & $\begin{array}{c}\text { Group C } \\
{[\mathrm{Me}]}\end{array}$ & $\begin{array}{c}\text { Control } \\
{[\mathrm{Me}]}\end{array}$ & $\mathrm{p}^{*}$ \\
\hline \multirow{13}{*}{ 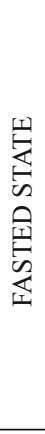 } & HR [bpm] & 67.8 & 70.2 & 66.8 & 64.01 & NS \\
\hline & $\mathrm{sBP}[\mathrm{mmHg}]$ & 114.1 & 116.6 & 120.1 & 104.5 & $0.007^{1,2,3} / 0.01^{5}$ \\
\hline & $\mathrm{dBP}[\mathrm{mmHg}]$ & 72.2 & 74.3 & 76.9 & 69.1 & $0.01^{2,3}$ \\
\hline & $\mathrm{mBP}[\mathrm{mmHg}]$ & 88.8 & 93.2 & 96.9 & 84.03 & $0.01^{2,3} / 0.04^{4,5}$ \\
\hline & $\mathrm{BRS}[\mathrm{ms} / \mathrm{mmHg}]$ & 9.6 & 11.1 & 13.3 & 23.3 & $0.0000^{1,2,3} / 0.04^{5,6}$ \\
\hline & BEI [\%] & 41.8 & 43.8 & 52.03 & 70.7 & $0.000^{1,2,3} / 0.02^{5,6}$ \\
\hline & LFnu-RRI [\%] & 60.4 & 55.7 & 57.6 & 51.8 & $0.001^{1} / 0.01^{2,3,4,5}$ \\
\hline & HFnu-RRI [\%] & 39.6 & 44.3 & 42.4 & 48.2 & $0.01^{1,2,3} / 0.01^{4}$ \\
\hline & VLF-RRI [ms²] & 200.9 & 228.8 & 192.5 & 306.6 & $0.01^{1,2} / 0.001^{3}$ \\
\hline & LF-RRI $\left[\mathrm{ms}^{2}\right]$ & 113.4 & 88.7 & 201.4 & 311.7 & $0.002^{1,2,3} / 0.01^{5,6}$ \\
\hline & HF-RRI [ms $\left.{ }^{2}\right]$ & 92.1 & 91.8 & 111.6 & 346.2 & $0.001^{1,2,3} / 0.03^{5,6}$ \\
\hline & PSD-RRI [ms²] & 555.2 & 579.6 & 607.3 & 1189.1 & $0.001^{1,2,3} / 0.04^{5,6}$ \\
\hline & LF/HF-RRI & 2.4 & 1.51 & 1.6 & 1.21 & $0.001^{1,3} / 0.01^{4,5,6}$ \\
\hline \multirow{13}{*}{ 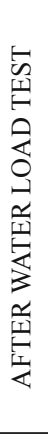 } & HR [bpm] & 62.9 & 65.7 & 64.5 & 62.4 & NS \\
\hline & $\mathrm{sBP}[\mathrm{mmHg}]$ & 109.6 & 122.9 & 123.1 & 104.8 & $0.004^{1,2,3} / 0.01^{5}$ \\
\hline & $\mathrm{dBP}[\mathrm{mmHg}]$ & 72.8 & 77.9 & 77.1 & 68.1 & $0.007^{1,2,3}$ \\
\hline & $\mathrm{mBP}[\mathrm{mmHg}]$ & 87.5 & 97.02 & 95.9 & 83.1 & $0.007^{1,2,3} / 0.04^{4,5}$ \\
\hline & $\mathrm{BRS}[\mathrm{ms} / \mathrm{mmHg}]$ & 8.79 & 10.6 & 10.7 & 17.3 & $0.0001^{1,2,3} / 0.04^{5,6}$ \\
\hline & BEI $[\%]$ & 52.2 & 51.1 & 55.05 & 68.1 & $0.0000^{1,2,3 / 0.02^{5,6}}$ \\
\hline & LFnu-RRI [\%] & 54.8 & 54.8 & 61.4 & 50.5 & NS \\
\hline & HFnu-RRI [\%] & 45.2 & 45.2 & 38.6 & 49.5 & NS \\
\hline & VLF-RRI [ $\left.\mathrm{ms}^{2}\right]$ & 255.7 & 256.8 & 372.6 & 909.1 & $0.01^{1,2,3}$ \\
\hline & LF-RRI $\left[\mathrm{ms}^{2}\right]$ & 243.1 & 192.8 & 377.2 & 615.4 & $0.02^{1,2,3} / 0.04^{4,5,6}$ \\
\hline & HF-RRI [ms $\left.{ }^{2}\right]$ & 211.7 & 145.7 & 201.9 & 564.7 & $0.02^{1,2,3} / 0.04^{4,5,6}$ \\
\hline & PSD-RRI [ms $\left.{ }^{2}\right]$ & 753.1 & 857.1 & 841.9 & 2424.1 & $0.006^{1,2,3} / 0.01^{4,5}$ \\
\hline & LF/HF-RRI & 1.5 & 1.3 & 1.8 & 1.09 & $0.04^{1,2,3} / 0.04^{5,6}$ \\
\hline
\end{tabular}

$\mathrm{Me}-$ median value, $\mathrm{p}<0.05$ (ANOVA analysis): $\mathrm{p}^{1}$ - differences group A vs the controls; $\mathrm{p}^{2}$ - differences group $\mathrm{B}$ vs the controls; $\mathrm{p}^{3}$ - differences group $\mathrm{C}$ vs the controls; $\mathrm{p}^{4}$ - differences group A vs group B; $\mathrm{p}^{5}-$ differences group A vs group $\mathrm{C} ; \mathrm{p}^{6}$ - differences group $\mathrm{B}$ vs group $\mathrm{C}$

(LF: 201.4 vs $311.7 \mathrm{~ms}^{2}, \mathrm{p}=0.001$; HF: 111.6 vs $346.2 \mathrm{~ms}^{2}, \mathrm{p}=$ 0.001). After the WLT, a two-fold increase was observed in the values of both HRV parameters (Fig. 2). Detailed results are presented in Table 2.

\section{BPV analysis}

Compared with the controls, gastric, colon and rectal cancer patients presented with lower values of most spectral parameters for systolic and diastolic BPV determined at rest. The only exceptions were LFnu-sBP and LF/HF-sBP the values of which in rectal cancer patients were higher than in the controls. The differences in diastolic BPV indices followed a similar pattern. After the WLT, LFnu-dBP, LFnu-sBP and LF/HF-sBP values in rectal cancer patients were significantly higher than in other groups. The results are shown in Figure 3.

\section{Analysis of cardiovascular hemodynamics}

While no significant differences in HR were observed between the study groups, fasting systolic and diastolic BP in cancer patients were significantly higher than in the controls. Analysis of baroreceptor sensitivity demonstrated that gastric, colon and rectal patients presented with significantly lower values of BRS and BEI than the controls. This observation corresponded to sympathetic overactivity. After the WLT, the relationship between hemodynamic parameters of cancer patients and controls was essentially the same as before the test. While no significant post-WLT changes in hemodynamic parameters were observed in the controls, a decrease in HR occurred in all cancer patient groups. Additionally, a significant increase in BEI values was observed in gastric and colon cancer patients. The results are shown in Table 2.

\section{Other analyses}

Additional analysis was done. Responses to the WLT in all study groups were analyzed according to age, sex, type of therapy (palliative vs radical), treatment modality (systemic therapy vs no chemotherapy) and locations of the primary tumor. Regardless of the cancers group, no association was found between sex and the volume of water ingested during the WLT.

Gastric cancer patients who underwent partial gastrectomy ingested significantly less water than those who did not receive this type of treatment: $417 \pm 127 \mathrm{ml}$ vs 500 $\pm 0 \mathrm{ml}(\mathrm{p}=0.02)$. Additionally, the surgically-treated gastric cancer patients presented with enhanced sympathetic activity when compared with those who did not undergo gastrectomy $(\mathrm{LF} / \mathrm{HF} 1.63 \pm 1.15$ vs $1.02 \pm$ $0.49, \mathrm{p}=0.02)$.

The HF value in gastric cancer patients older than 65 years was significantly higher than in younger patients with this malignancy ( 251.4 vs $80.3 \mathrm{~ms}^{2}, \mathrm{p}=0.02$ ). Furthermore, the older gastric cancer patients presented with significantly lower LF/HF values than the younger ones (1.62 vs 2.71, $\mathrm{p}=0.03$ ) whereas an opposite phenomenon was observed in the control group. No statistically significant differences were found between the parameters of patients treated with chemotherapy and without and those who received chemoradiotherapy. Similarly, no significant differences were observed in the parameters of palliatively and radically treated patients.

Colon cancer patients who underwent primary cytoreductive surgery ingested less water during the WLT than non-operated patients with this malignancy $(420 \pm 125 \mathrm{ml}$ vs $500 \pm 0 \mathrm{ml}, \mathrm{p}=$ 0.03 ) and presented with increased sympathetic tone (LF/HF 1.88 \pm 1.02 vs $1.22 \pm 0.87, \mathrm{p}=0.001)$. Furthermore, the type of therapy exerted a significant effect on the outcome of the HRV analysis, with colon patients after radical therapy having significantly higher LF values than those treated in a palliative setting $(\mathrm{p}=0.016)$.

None of the analyzed grouping variables exerted a significant effect on the outcomes of WLT in rectal cancer patients.

\section{Discussion}

To the best of our knowledge, this is the first study to analyze a relationship between the autonomic system activity, estimated 

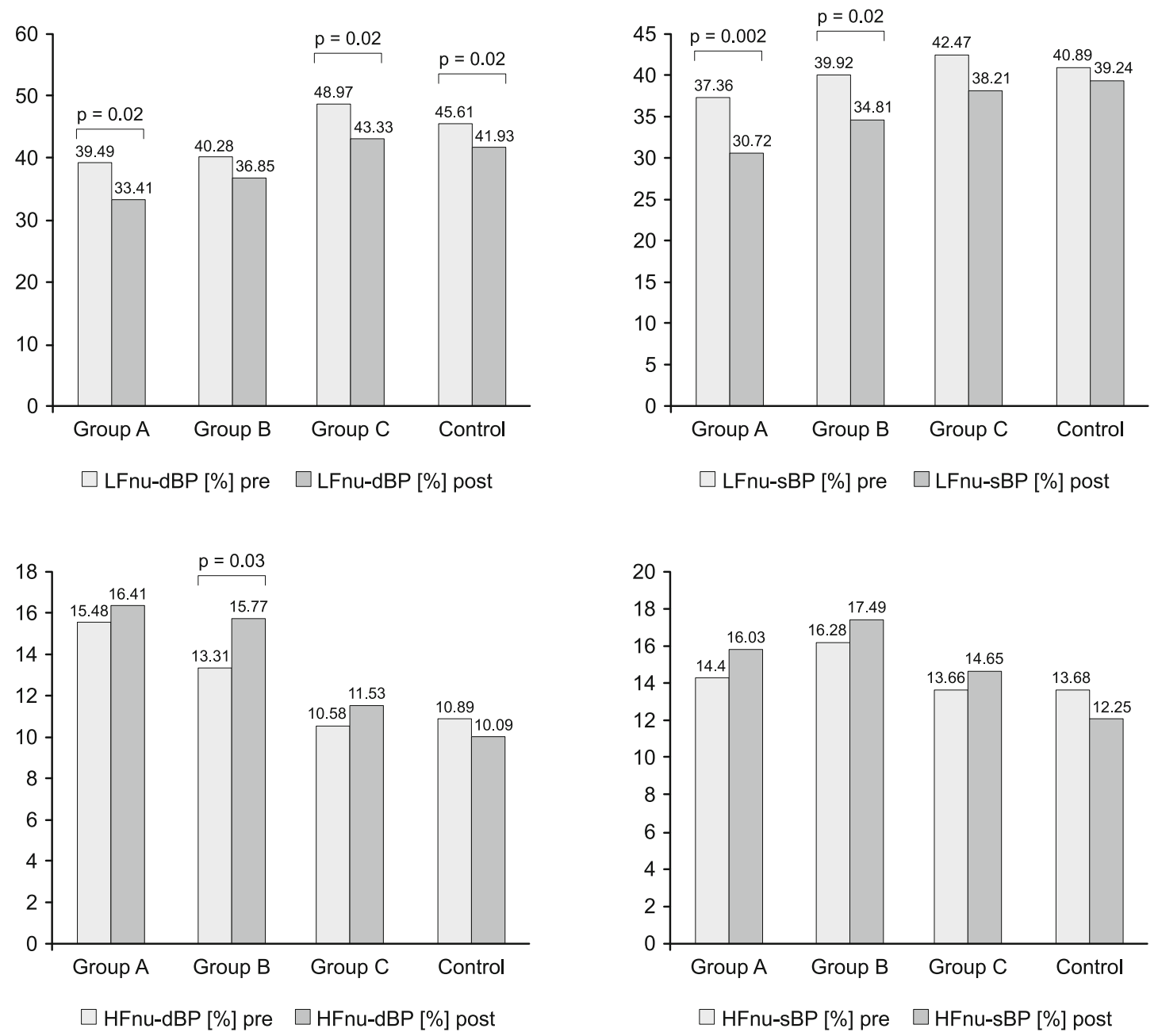

Fig. 3. Spectral systolic and diastolic BPV indices (LFnu and HFnu) in patients with various gastrointestinal malignancies and healthy controls, determined in a fasted state after WLT. $p<0.05$ - the Wilcoxon singed rank test, pre - before WLT, post - after WLT.

based on HRV and BPV parameters, cardiovascular indices, baroreceptor sensitivity and gastric myoelectric activity in patients with gastrointestinal malignancies who had been subjected to the WLT, a test which can evoke visceral reception. We analyzed the effect of WLT-activated visceral reception on myoelectric activity of the stomach and autonomic activity in gastrointestinal malignancies. Principal findings of this study can be summarized as follows:

1) In healthy controls, WLT contributed to a significant increase in ACSWC and arrhythmia. In turn, DF and the percentage of normogastria were significantly decreased. The percentage of bradygastria and tachygastria time remained unchanged.

2) A decrease in the percentage of normogastria time and an increase in bradygastria time percentage were observed in gastric cancer patients. In colon and rectal cancer patients, a significant increase in the percentage of normogastria time and a non-significant increase in slow wave coupling were documented, but none of those parameters reached the values observed in the controls.
3) Compared with the controls, cancer patients presented with significantly lower values of resting HRV indices determined on linear analysis: LF, HF. A significant post-WLT increase in all these parameters was observed in colon and rectal cancer patients.

4) The post-WLT changes in hemodynamic indices corresponded to sympathetic activation in the colon and rectal cancer patients.

5) The responses to WLT in all the study groups were stratified according to age, sex, type of therapy (palliative vs radical), the inclusion of systemic therapy in the treatment protocol and location of the primary tumor. A significant correlation between the response to WLT, age and type of therapy was found in gastric cancer patients. Furthermore, a statistically significant difference was observed in the responses to WLT in colon cancer patients who underwent primary cytoreductive surgery and those who did not.

The results of this study suggest that patients with gastrointestinal malignancies might present with an autonomic imbalance 
in the form of sympathetic overactivity. These abnormalities were reflected by disturbances of cardiovascular hemodynamics and baroreceptor sensitivity observed at rest. The hereby presented findings are consistent with the results of our previous studies $(14,21,22)$. Importantly, the altered response to the WLT was observed, though approximately three-fourths of our patients with gastrointestinal malignancies underwent a cytoreductive surgery. Finally, the responses to WLT were specific for primary tumor location.

According to literature, patients with functional dyspepsia, severe dyspeptic symptoms after Nissen fundoplication, dysmotilitylike functional dyspepsia, reflux disease, active gastric ulcers and gastroesophageal reflux disease (GERD) with grade A esophagitis had significantly lower water intake than healthy subjects and presented with more dyspeptic symptoms $(2,3,4,5,6,32,33)$. Moreover, WLT was shown to distinguish accurately functional dyspepsia with intact gastric function but the abnormal visceral perception from other gastrointestinal disorders (2). The results of our study are consistent with those findings since gastric cancer patients showed more evident disturbances in response to the WLT than individuals with colorectal malignancies and healthy controls. Previous studies demonstrated a significant association between the maximal ingested volume of water and the occurrence of gastrointestinal symptoms, such as nausea and fullness, in patients with functional dyspepsia. No significant correlation was observed between patient sex and maximal volume of ingested water (6).

However, in another study, drinking capacity was shown to depend on sex, with significantly higher maximal water intake observed in men with functional dyspepsia than in women with this condition (11). Regardless of the location of the primary tumor, we found no correlation between sex, age and volume of water ingested during the WLT. According to literature, male patients with GERD ingested significantly more water than women (6). In turn, obese patients, especially those with body mass index (BMI) $>30 \mathrm{~kg} / \mathrm{m}^{2}$, had significantly higher maximal water consumption than healthy volunteers with normal BMI (34). We did not analyze maximal water consumption in our present study but instead focused on the response to 5-minute WLT. Nevertheless, we noted that some patients, especially those with gastric malignancies, ingested less than $500 \mathrm{ml}$ of water during the WLT.

According to Konishi et al, patients with nausea and general symptoms of early dumping had significantly smaller reservoir capacity. Furthermore, patients with early satiation and abdominal symptoms of early dumping were shown to have significantly impaired tolerance to volume loading during the WLT. The same study demonstrated that postoperative impairment of GI function was closely related to symptoms (35). The results of our present experiment suggest that gastric cancer patients experienced more disturbances during the WLT that individuals with gastrointestinal malignancies of other locations. The water intake in gastric and colon cancer patients was lower than in persons with rectal malignancies and healthy controls. In the case of gastric patients, this relationship corresponded well with a history of partial gastrectomy and sympathetic overactivity. Our findings are consistent with the results published by Parkman et al in the study conducted by those authors, mean water intake in patients with gastroparesis and functional dyspepsia was significantly lower than in healthy control. The lesser water intake during the WLT was associated with more severe symptoms of early satiety and postprandial fullness (36).

To the best of our knowledge, there are only a few published studies analyzing a link between cancer and gastrointestinal motility. According to the Sachveda et al, patients with gallbladder cancer and vomiting had a significantly higher volume of aspirate on saline load test than the patients who did not vomit. The amplitudes of contractions in the antrum and duodenum were significantly lower in gallbladder cancer patients than in healthy volunteers. Moreover, these patients presented with significantly lower fasting and postprandial values of antral motor indices than the controls. Patients with vomiting showed significantly lower values of contraction amplitude and motility indices than those who did not vomit. These findings should be probably interpreted as a consequence of antroduodenal motility disturbances (37). In other study gastric emptying after solid meal after esophageal reconstruction surgery with gastric or colonic tube in oncological patients was faster than in healthy subjects. The half emptying time was the same in both groups of patients (35). On the other hand, patients with early gastric cancer treated with segmental gastrectomy had prolonged solid meal gastric emptying even one year after gastric operation. In turn, the half emptying time for liquid meal was shortened at the same period of time (38).

Furthermore, all patients included in our study, but not healthy controls, showed alterations of stomach fullness in response to the WLT. Patients with gastric and colon malignancies presented with significantly higher percentages of gastric dysrhythmia time and appeared to be more sensitive to gastric distension during the WLT (5).

Our previous study investigated an association between gastric myoelectric activity disturbances in response to meal showed in colon, rectal and gastric cancer patients similarly lower percentages of normogastria time, lower percentages of ACSWC and higher values of DP than the controls in a fasted state. In response to meal no improvement in the percentage of normogastria time, DP, DF and ACSWC was observed in patients with GI malignancies (13). The response to meal was disturbed in gastrointestinal malignancies, but the analysis effect of the WLT better presented dysfunction of neurological regulation GI motility. Despite a noncaloric meal, WLT caused changes in electrogastrography in patients with GI cancers. These findings imply that the cause of the abnormalities might be either the primary visceral pathology or a more central mechanism, perhaps in association with psychological disturbances; our study did not provide enough evidence to answer this question unequivocally.

Alternations of myoelectric activity in colon and rectal cancer patients observed at rest and after the WLT might be an effect of chemotherapy. McQuade et al demonstrated that administration of 5-Fu was reflected by the acceleration of gastrointestinal transit associated with acute intestinal inflammation observed on the third day after the treatment. Hence, 5-Fu might induce persistent changes in the ENS and resultant gastrointestinal dysfunc- 
tion, such as delayed gastrointestinal transit, delayed gastric and intestinal emptying, and colonic dysmotility (39). Our patients received 5-Fu-based chemotherapy as a causal systemic treatment for gastrointestinal malignancies. An underlying mechanism of myoelectric activity alternations observed in participants of our study might be the loss of myoenteric neurons and/or inflammatory response which triggered functional changes in the gastrointestinal tract. However, we did not demonstrate a direct link between EGG alterations and anticancer therapy. The discrepancies between the results of our study and findings published by McQuade et al might be related to the fact that those authors conducted their experiment in a rodent model, not in humans.

Only one study analyzed relation between radiotherapy in cancer patients and myoelectric gastric activity so far. Gastric myoelectrical activity is normal in untreated esophageal cancer. Neoadjuvant chemoradiotherapy in esophageal cancer patients caused abnormal gastric myoelectrical activity involving significantly increased tachygastria and decreased motility. After surgery bradygastria increased which persisted at 6 months (40). In our study radiotherapy underwent $28(35 \%)$ patients. The analysis of WLT response did not show significant differences in gastric myoelectic activity and autonomic function in GI cancer patients pretreated with radiotherapy.

In our present study, pressor response occurred 5 min after water ingestion, reached its peak within 30-40 min, and depending on the study group, persisted even longer than one hour. In a previous study of healthy elderly, ingestion of tap water (approximately $500 \mathrm{ml}$ ) caused a slight increase in systolic blood pressure, up to $11 \mathrm{mmHg}$ above the baseline (30). In contrast, water ingestion did not elicit a pressor response in healthy young subjects (40). In our present study, we did find a relationship between age and response to WLT. Nevertheless, a pressor response was observed in all groups of cancer patients, with the most evident abnormalities found in persons with gastric and colon malignancies.

One potential limitation of this study is the lack of published data on the influence of WLT on gastrointestinal and cardiovascular function in cancer patients after chemotherapy and/or surgical treatment.

As to the best of our knowledge, this study was the first one to analyze the effect of visceral reception activation on autonomic activity and myoelectric activity of the stomach in patients with gastrointestinal malignancies, we have no benchmark for our findings. We hope that the results presented in this paper will stimulate further research on the relationship between neoplastic disease, autonomic activity and gastrointestinal motility.

\section{Conclusion}

A slight predominance of the sympathetic component was observed in response to WLT, which was also reflected by changes in hemodynamic parameters. The response to WLT is a consequence of GI mechanoreception and osmoreception activation and resultant pressure reaction. This complex response might be disrupted by the neoplastic process within the GI tract, especially in gastric and colon malignancies, but not in rectal cancer.

\section{References}

1. Routledge HC, Chowdhary S, Coote JH, Townen JN. Cardiac vagal response to water ingestion in normal human subjects. Clin Sci (Lond) 2002; 103 (2): 157-162.

2. Koch KL, Hong SP, Xu L. Reproducibility of gastric myoelectrical activity and the water load test in patients with dysmotility-like dyspepsia symptoms and in control subjects. J Clin Gastroenterol 2000; 31 (2): $125-129$.

3. Jones MP, Hoffman S, Shah D, Patel K, Ebert CC. The water load test: observations from healthy controls and patients with functional dyspepsia. Am J Physiol Gastroenterol Liver Physiol 2003; 284 (6): G896-G904.

4. Jones MP, Roth LM, Crowell MD. Symptom reporting by functional dyspeptics during the water load test. Am J Gastroenterol 2005; 100 (6): 1334-1339.

5. Chen CL, Hu CT, Lin HH, Yi CH. Clinical utility of electrogastrography and the water load test in patients with upper gastrointestinal symptoms. J Smooth Muscle Res 2006; 42 (5): 149-157.

6. Chen CL, Lin HH, Chen MC, Huang LC. Dyspeptic symptoms and water load test in patients with functional dyspepsia and reflux disease. Scan J Gastroenetrol 2005; 40 (1): 28-32.

7. Raj SR, Biaggioni I, Black BK et al. Sodium paradoxically reduces the gastropressor response in patients with orthostatic hypotension. Hypertension 2006; 48 (2): 329-334.

8. Scott EM, Greenwood JP, Gilbey SG, Stoker JB, Mary DA. Water ingestion increases sympathetic vasoconstrictor discharge in normal human subjects. Clin Sci Colch 2001; 100 (3): 335-342.

9. Tank J, Schroeder C, Stoffels M et al. Pressor effect of water drinking in tetraplegic patients may be a spinal reflex. Hypertension 2003; 41 (6): 1234-1239.

10. Strid $\mathbf{H}$, Norstrom $\mathbf{M}$, Sjoberg $\mathbf{J}$ et al. Impact of sex and psychological factors on the water loading test in functional dyspepsia. Scand J Gastroenterol 2001; 36 (7): 725-730.

11. Yin J, Chen JD. Electrogastrography: methodology, validation and applications. J Neurogastroenterol Motil 2013; 19 (1): 5-17.

12. Chasen M, Bhargava R. Gastrointestinal symptoms, electrogastrography, inflammatory markers, and PG-SGA in patients with advanced cancer. Support Care Cancer 2012; 20 (6): 1283-1290.

13. Zygulska AL, Furgala A, Krzemieniecki K, Wlodarczyk B, Thor P. Association between gastric myoelectric activity disturbances and dyspeptic symptoms in gastrointestinal cancer patients. Adv Med Sci 2019; 64 (1): 44-53.

14. Hellstrom PM, Geliebter A, Naslund E et al. Peripheral and central signals in the control of eating in normal, obese and binge-eating human subjects. Br J Nutr 2004; 92 Suppl 1: S47-S57.

15. Levanon D, Zhang M, Orr WC, Chen JD. Effect of meal volume and composition an gastric myoelectrical activity. Am J Physiol 1998; 274 (2): G430-G434.

16. Arroyo-Carmona RE, Lopez-Serrano AL, Albarado-Ibanez A et al. Heart rate variability as early biomarker for the evaluation of diabetes mellitus progress. J Diabetes Res 2016; 2016: 8483537. DOI: 10.1155/2016/8483537.

17. Davydow DM, Naliboff B, Shahabi L, Shapiro D. Baroreflex mechanisms in irritable bowel syndrome: Part I. Traditional indices. Physiol Behav 2016; 157: 102-108. 
347-356

18. Maheshwari A, Norby FL, Soliman EZ et al. Low heart rate variability in a 2-minute electrocardiogram recording is associated with an increased risk of sudden cardiac death in the general population: the atherosclerosis risk in communities study. Plos One 2016, 11(8):e0161648. DOI: 10.1371/journal.pone.0161648.

19. Walsh D, Nelson KA. Autonomic nervous system dysfunction in advanced cancer. Support Care Cancer 2002; 10 (7): 523-528.

20. Zygulska AL, Furgala A, Krzemieniecki K. Correlation between the autonomic nervous system and neoplastic disease. Eur J Oncol 2018; 23 (1): 5-18.

21. Zygulska AL, Furgala A, Krzemieniecki K, Wlodarczyk B, Thor P. Autonomic dysregulation in colon cancer patients. Cancer Invest 2018; 36 (5): 255-263.

22. Furgala A, Thor PJ, Mazur M, Pach R, Matyja A, Kulig J. Gastric motility disorders in patients after pancreatoduoadenectomy. Folia Med Cracov 2008; 49 (3-4): 37-48.

23. Imai K, Sakita M. Pre- and postoperative electrogastrography in patients with gastric cancer. Hepatogastroenterology 2005; 52 (62): 639-644.

24. Thor PJ, Furgala A, Pach $\mathbf{R}$ et al. Antral gastric motility impairement and autonomic nervous system dysfunction in patients with pancreatic cancer (preliminary results). Folia Med Cracov 2006; 47 (1-4): 61-68.

25. Simonian HP, Panganamamula K, Parkman HP et al. Multichannel electrogastrography (EGG) in normal subjects: a multicenter study. Dig Dis Sci 2004; 49 (4): 594-601.

26. Wang ZS, Elsenbruch S, Orr WC, Chen JD. Detection of gastric slow wave uncoupling from multi-channel electrogastrogram: validations and applications. Neurogastroenterol Motil 2003; 15 (5): 457-465.

27. Krusiec-Świdergoł B, Jonderko K. Multichannel electrogastrography under a magnifying glass - an in-depth study on reproducibility of fed state electrogastrograms. Neurogastroenterol Motil 2008; 20 (6): 625-634.

28. Kasicka-Jonderko A, Jonderko K, Krusiec-Swidergol B, Obrok I, Blonska-Fajfrowska B. Comparison of multichannel electrogastrograms obtained with the use of three different electrode types. J Smooth Muscle Res 2006; 42 (2-3): 89-101.

29. Sassi R, Cerutti S, Lombardi F et al. Advances in heart rate variability signal analysis: joint position statement by the e-Cardiology ESC Working Group and the European Heart Rhythm Association co-endorsed by the Asia Pacific Heart Rhythm Society. EP Europace 2015; 17 (9): 1341-1353.
30. Jordan J, Shannon JR, Black BK et al. The pressor response to water drinking in humans: a sympathetic reflex? Circulation 2000; 101 (5): 504-509.

31. Buccelletti F, Bocci MG, Gilardi E et al. Linear and nonlinear heart rate variability indexec in clinical practice. Comput Math Methods Med 2012. Article ID 219080, DOI.org/ 10.1155/ 2012/219080.

32. Remes-Troche JM, Montano-Loza A, Martinez JC, Herrera M, Valdovinos-Diaz MA. Drinking capacity and severity of dyspeptic symptoms during a water load test after Nissen fundoplication. Dig Dis Sci 2007; 52 (10): 2850-2857.

33. Schurman JV, Friesen CA, Andre L et al. Diagnostic utility of the water load test in children with chronic abdominal pain. J Pediatr Gastroenterol Nut 2007; 44 (1): 51-57.

34. Mejia-Rivas M, Remes-Troche J, Montano-Loza A, Herrera M, Valdovinos-Diaz MA. Gastric capacity is related to body mass index in obese patients. A study using the water load test. Rev Gastroenterol Mex 2009; 74 (1): 71-73.

35. Konishi H, Nakada K, Kawamura $M$ et al. Impaired gastrointestinal function affects symptoms and alimentary status in patients after gastrectomy. World J Surg 2016; 40 (11): 2713-2718.

36. Parkman HP, Hallinan EK, Hasler WL et al. Gastroparesis Clinical Research Consortium. Early satiety and postprandial fullness in gastroparesis correlate with gastroparesis severity, gastric emptying, and water load testing. Neurogastroenterol Motil 2017; (4): 29:e12981.

37. Sachdeva S, Ghoshal UC, Saraswat VA, Das K, Misra A. Gastroduodenal dysmotility in patients with gallbladder carcinoma: frequency of occurrence and clinical importance. Natl J Med India 2006; 19 (1): 4-9.

38. Fonseca L, Maliska CM, Cruz MG, Castro L, Gutfilen B. Esophageal reconstruction surgery in oncologic patients: determination of gastric emptying time. J Clin Exp Cancer Res 2000; 19 (2): 137-140.

39. McQuade RM, Stojanovska V, Donald E, Abalo R, Bornstein JC, Nurgali K. Gastrointestinal dysfunction and enteric neurotoxicity following treatment with anticancer chemotherapeutic agent 5-fluorouracil. Neurogastroenterol Motil 2016; 28 (12): 1861-1875.

40. Lawlor PM, McCullough JA, Byrne PJ, Reynolds JV. Gastric myoelectrical activity post-chemoradiotherapy and esophagectomy: a prospective study using subscapular surface recording. Dis Esophagus 2004; 17 (1): 76-80. 